\title{
Experiências artísticas instrumentalizadas por processos cognitivos: um aporte teórico-hermenêutico
}

\section{Artistic experiences manipulated by cognitive processes: a theoretical-hermeneutic contribution}

\begin{abstract}
Prof $^{\mathrm{a}} \mathrm{M}^{\mathrm{a}}$ Aparecida Camargo cidascamargo@gmail.com Unicruz
\end{abstract}

\author{
Prof $^{\text {a }}$ Ieda Linck \\ imdlinck@gmail.com \\ Unicruz
}

Dnd $^{\text {a }}$. Vanessa Neubauer

borbova@gmail.com

Unisinos

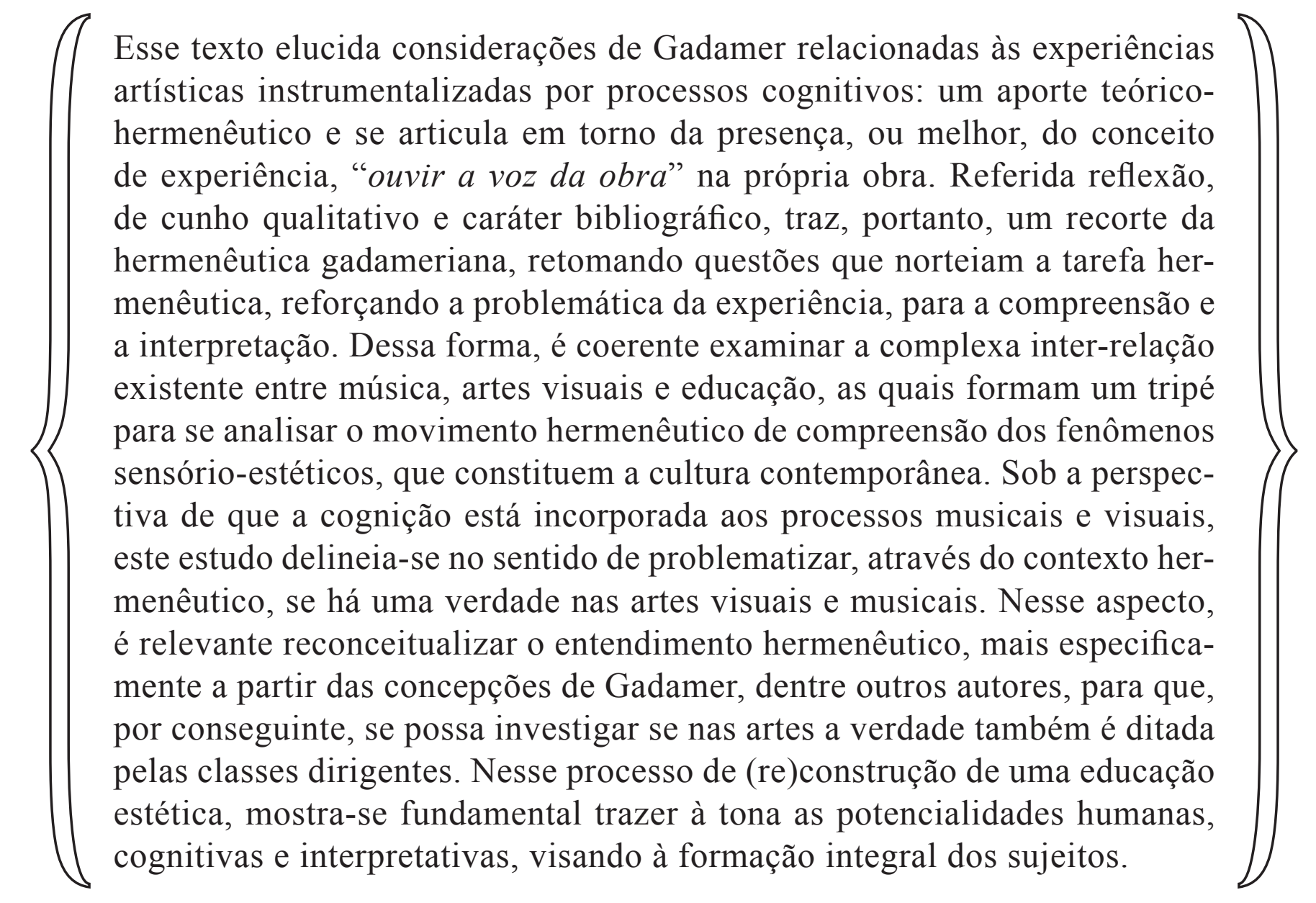

PALAVRAS-CHAVE Arte . Cultura . Educação . Verdade 
This text elucidates Gadamer considerations related to artistic experiences manipulated by cognitive processes: a theoretical and hermeneutical contribution and is built around the presence, or rather the concept of experience, "the voice of labor" in the work itself. Said reflection, a qualitative study and bibliographical, thus brings a clipping of Gadamer's hermeneutics, referring questions to guide the hermeneutical task, reinforcing the problematic of experience in understanding and interpretation. Thus, it is logical to examine the complex interrelationship between music, visual arts and education, which form a tripod to analyze the movement of hermeneutic understanding of sensory-aesthetic phenomena that constitute contemporary culture. From the perspective that cognition is embodied the musical and visual processes, this study outlines in the sense of questioning, through the hermeneutic context, if there is truth in the visual and musical arts. In this respect it is relevant to reconceptualize the hermeneutic understanding, more specifically from the conceptions of Gadamer, among others, so therefore we can investigate whether the truth in the arts is also dictated by the ruling classes. In this (re)construction of an aesthetic education process has proven crucial to bring out the human, cognitive and interpretative capabilities, aiming at the integral formation of the subject.

KEYWORDS Art. Culture . Education. Truth 
Dnda. Vanessa Neubauer [Unisinos ]
Prof ${ }^{-a}{ }^{-a}$ Aparecida Camargo

[Unicruz ]
Prof ${ }^{a}$ Ieda Linck

[Uncruz]

\section{Introdução}

Tanto na arte quanto na tradição histórica, deparamo-nos com fenômenos hermenêuticos por excelência. Na arte, toda e qualquer relação com a obra sempre envolve necessariamente um processo interpretativo no interior do qual o que está a cada vez em jogo é determinar o que a obra tem efetivamente a nos dizer. Já na tradição histórica, vemos imediatamente em questão a suposta distância daquilo que nos é respectivamente legado. Quer se trate de um documento histórico ou de um texto legado pela tradição, o fato de o documento ou o texto terem sido redigidos em um tempo diverso do nosso induz a pensar que a tarefa fundamental da interpretação seria justamente acessar a verdade contida nesse horizonte temporal já perfeito. O problema de tal suposição, contudo, é o próprio distanciamento que ela produz entre o que precisa ser interpretado e o acontecimento da interpretação. Se essa distância persiste, não há como escapar de um dilema estrutural (GADAMER, 2010, p. IX).

Seguindo essa compreensão, a atividade cognitiva musical pode ser considerada uma das experiências sensoriais mais antigas, visto que a emissão e a recepção de sons é uma das primeiras formas de contato com o mundo. É também nesse sentido que as artes pictóricas são analisadas como manifestações que retratam a convivência societal dos sujeitos. Dessa forma, é coerente examinar a complexa inter-relação existente entre música, artes visuais e educação, as quais formam um tripé para se analisar o movimento hermenêutico de compreensão dos fenômenos sensório-estéticos, que constituem a cultura contemporânea.

Sob a perspectiva de que a cognição está incorporada aos processos musicais e visuais, este estudo delineia-se no sentido de problematizar, através do contexto hermenêutico, se há uma verdade nas artes visuais e musicais. Nesse aspecto, é relevante reconceitualizar o entendimento hermenêutico, mais especificamente a partir das concepções de Gadamer, dentre outros autores, para que, por conseguinte, se possa investigar se nas artes a verdade também é ditada pelas classes dirigentes. Nesse processo de (re)construção de uma educação estética, mostra-se fundamental trazer à tona as potencialidades humanas, cognitivas e interpretativas, visando à formação integral dos sujeitos. Conforme refere Gadamer (2010, p. 04), não é nenhuma metáfora para a obra de arte que ela nos diga algo e pertença enquanto algo que diz algo ao contexto de tudo aquilo que temos de compreender. Ao contrário, esse fato possui um bom sentido que pode ser apresentado. Com isso, contudo, a obra de arte se mostra como objeto da hermenêutica. 
Dnda. Vanessa Neubauer [Unisinos ]
Prof ${ }^{-a}$ Ma Aparecida Camargo

[Unicruz ]
Prof ${ }^{\mathrm{a}}$ Ieda Linck

[Uncruz]

\section{A experiência da obra de arte e a interpretação estética}

A partir desse viés, as reconceitualizações hermenêuticas perpassam pela compreensão da obra Verdade e Método, de Hans-Georg Gadamer. A intenção da terminologia "hermenêutica", na ótica de Gadamer (2007, pp. 14-15), não é desenvolver uma doutrina da arte como sistema de regras artificiais, mas sim pensar o que fazemos, o que deveríamos fazer e o que acontece além do querer; tudo isso em uma conjuntura filosófica. O cerne da questão não é negar o caráter imprescindível do trabalho metodológico na construção da obra, mas conscientizar sobre algo que está encoberto ou ignorado pela disputa dos métodos, sendo que o movimento da compreensão é abrangente e universal, residindo na natureza da própria coisa.

Neste domínio hermenêutico, ainda em conformidade com Gadamer (2007, p. 16), a questão da qualidade estética está nas leis da construção e dispõe de um nível de formulação que ultrapassa as barreiras de procedência histórica e de presença cultural. Pode-se questionar o sentido que a qualidade representa face à obra de arte, ou seja, uma possibilidade independente de conhecimento. Isso conduz à afirmação de que o gosto, o belo, o feio, o talento e a criatividade não são "dons" ou "manifestações divinas", mas efetivamente manifestações introjetadas culturalmente.

A reflexão filosófica em torno da arte se encaminhou, assim, para uma ciência que fez da apreciação da beleza o seu tema fundamental. Fruto de certas tendências manifestadas no pensamento teórico desde o século XVII, a nova ciência concebeu a arte como aquele produto da atividade humana que, obedecendo a determinados princípios, tem por fim produzir artificialmente os múltiplos aspectos de uma só beleza universal, apanágio das coisas naturais, de acordo com o que elucida Nunes (2005, p. 10).

Por sua vez, Camargo (2009, p. 61) afirma que os cânones estéticos têm uma longa história, que se iniciou no mundo antigo. Desde então, vêm sendo utilizados muitos elementos e ingredientes para a confecção e perpetuação desses modelos, em torno dos quais se formaram muitas ideias equivocadas e distorcidas e que, por conta disso, provocam acirrados debates. Nessa linha de argumentação, pesquisar as práticas de produção artística e seu ensino implica estudar as convenções estéticas que perpassam este campo e que são transmitidas por meio da educação, escolar ou não.

Sob esse mesmo aspecto, assevera Trevisan (1990, p. 09) que talvez mais importante seja persuadir as pessoas de que a arte é, antes de tudo, uma expe- 
Dnda. Vanessa Neubauer [Unisinos]
Prof ${ }^{a} M^{a}$ Aparecida Camargo

[Unicruz ]
Prof ${ }^{\mathrm{a}}$ Ieda Linck

[Uncruz]

riência ao alcance de qualquer indivíduo, e que o estudo de sua história e da estética reserva surpresas aos que desejam penetrar-lhes a intimidade. Sob este ponto de vista, Camargo (2009, p. 63) revela que o entendimento do que seja a arte sempre teve por base certas regras que outros estabeleceram antes de nós, existindo, então, um modelo, um cânone pré-fixado do que é a arte e do que é o artista desde a arte dos antigos gregos.

Assim, nesse processo de desconstrução e reformulação de concepções estéticas, todo aquele que experiencia a obra de arte internaliza o significado artístico desta de acordo com suas vivências socioculturais. Tal compreensão abarca a experiência da obra de arte e ultrapassa todo historicismo no domínio da experiência estética. Consequentemente, o movimento do ato de compreender não pode ser restrito ao desfrute reflexivo, estabelecido pela diferenciação estética, já que a universalidade do aspecto hermenêutico não se guia pela arbitrariedade. Logo, a experiência da obra de arte sempre ultrapassa, de modo fundamental, todo horizonte subjetivo da interpretação, tanto para quem a concebe quanto para quem a experiencia.

O artista, em consonância com Meira (2003, p. 94), é um mostrador de afetos, inventor de afetos, criador de afetos, em relação com os perceptos ou as visões que nos dá. Não é somente em sua obra que ele os cria, ele os dá para nós e nós transformamo-nos com eles. Ele nos imanta com suas formas e imagens, apanhando-nos na rede de suas composições. A imaginação tem o poder de outorgar a qualquer situação, acontecimento, fato, objeto, ser, função, a estrutura de uma forma plástica.

É interessante, por oportuno, trazer à discussão a teorização kantiana da validade universal estética como nos juízos da razão, pois o belo está "lá fora", como aduz Kant (1995). No entanto, no juízo estético, a concordância universal não é regida por normas, sendo apenas atribuída. O prazer com os objetos estéticos dá-se em virtude de sua "finalidade formal", em tese, um sentido de completação, de fechamento, que não é, evidentemente, característica exclusiva do senso estético. O belo agrada por sua forma, de modo subjetivo e não objetivo. Trata-se de uma satisfação para captar uma maneira dada na faculdade da imaginação, porém, o objeto estético, como finalidade formal subjetiva, não envolve nenhum pensamento acerca da perfeição do objeto. Por isso é que, para Kant (1995), o prazer sensorial é puramente subjetivo e envolve interesse, em contrapartida o prazer estético, embora igualmente subjetivo, é desinteressado e reflexivo. O prazer com a utilidade de algo implica ter em mente algum conceito de uso, de propósito, de fim prático, o belo, ao contrário, simplesmente satisfaz. 
Dnda. Vanessa Neubauer [Unisinos]
Prof ${ }^{a} M^{a}$ Aparecida Camargo

[Unicruz ]
Prof ${ }^{\mathrm{a}}$ Ieda Linck

[Uncruz]

Historicamente, a estética, sob o aspecto de mera "ciência da sensibilidade", chega ao seu fim no século XX e é, progressivamente, substituída por um discurso que conjuga racionalidade e afetividade de forma mais radical. Essa nova racionalidade é ela mesma estética, mas agora será preciso tentar compreender não mais através da dicotomia tradicional entre senso e sensível, mas como uma experiência simultânea de percepção sensível e percepção de sentido, conforme esclarece Feitosa (2004, p. 129).

Perfilhando este enfoque, Heidegger (2006) sugere que todo "sentir" já é desde sempre um sentir "entendedor", todo ver e ouvir já são ver e ouvir "compreendentes". Sempre ouvimos algo com sentido, seja uma motocicleta ou os sinos da igreja. Para ouvir apenas ruído sem significado, é preciso muita técnica e concentração. É preciso ressaltar que a recíproca também é válida, ou seja, todo pensamento já está, desde sempre, de alguma maneira, contaminado de algum sentimento, seja ele o amor, a alegria, o ódio, a tristeza, o entusiasmo, a admiração ou simplesmente o tédio.

Isso se traduz no fato de que a interpretação estética significa, necessariamente, o compreender interconectado entre História, Arte, Educação e os sistemas culturais contemporâneos, especialmente ao entender que, em arte, não existe uma única interpretação correta. É mister perceber, então, que, desde o princípio da construção da obra, organiza-se um processo de historicização interligado à tradição e à capacidade de observação das ambiências em que se está inserido. Isso irá refletir na estrutura das possibilidades discutíveis de interpretação da obra e do artista.

\section{A arte e a filosofia enquanto campos de estudos hermenêuticos}

Por esse caminho é que se pode explicitar acerca da existência de uma consciência hermenêutica determinada sob condições históricas, a qual é formada apropriando-se da tradição e cuja essência consiste em continuar reflexionando aquilo que é, naturalmente, transmitido e reproduzido. À medida que se procede ao questionamento sobre questões estético-visuais na sua interface com experiências musicais, é relevante que haja um distanciamento metodológico, notadamente para se alcançar uma apreciação consistente, crítica e fundamentada.

É central para esta fundamentação hermenêutica o círculo interpretativo tanto do todo quanto das partes. Consoante alude Gadamer (2007, pp. 22-24), a 
Dnda. Vanessa Neubauer [Unisinos ]
Prof ${ }^{a} M^{a}$ Aparecida Camargo

[Unicruz ]
Prof ${ }^{a}$ Ieda Linck

[Uncruz]

tradição histórica deve ser pensada como objeto de compreensão histórica ou de concepção filosófica. A finitude do compreender é o modo pelo qual a realidade, a resistência, o absurdo e o incompreensível alcançam validez. Sob este prisma, o ser que se pode compreender é a linguagem, mas não no sentido de domínio absoluto e nem de um comportamento absoluto. A compreensão vai além de meras opiniões, suposições ou daquilo que foi consagrado pela tradição. Levando em consideração os textos imagéticos, sonoros e rítmicos, esclarece o citado autor (GADAMER, 2007, p. 29) que "compreender e interpretar textos não são expediente reservado apenas à ciência, mas pertence claramente ao todo da experiência do homem no mundo. Na sua origem, o fenômeno hermenêutico não é, de forma alguma, um problema do método".

A fenomenologia da compreensão impregna não apenas toda a referência humana de mundo, mas representa uma validade própria também no terreno da Ciência, resistindo à tentativa de ser transformado em método da Ciência. Sob o olhar gadameriano (GADAMER, 2007, p. 31), o fato de experimentarmos a verdade em uma obra de arte fortalece a necessidade de advertência à consciência científica de reconhecer seus limites. Os estudos hermenêuticos que têm como ponto de partida a experiência da arte e da tradição histórica procuram analisar o fenômeno hermenêutico em toda sua envergadura. Importa reconhecer uma experiência de verdade que não deve ser só justificada filosoficamente, mas que seja ela própria uma forma de filosofar.

Com suporte nessas concepções, pode-se vislumbrar que os costumes de linguagem e de pensamento que se formam para o indivíduo face à tradição histórica exercem função primordial para a hermenêutica da arte. É a consciência crítica que deve acompanhar o filosofar responsável, colocando os costumes de linguagem e de pensamento, formados para o sujeito na comunicação com seu mundo circundante, diante do fórum desta tradição histórica da qual todos fazem parte.

Na contemporaneidade, a formação continuada dos sujeitos está, de forma estreita, vinculada às concepções socioculturais, a qual designa, antes de tudo, a maneira preponderadamente humana de aperfeiçoar aptidões e habilidades. Nesse conjunto, é relevante apropriar-se do pensamento kantiano quando refere que a cultura da faculdade é, como tal, um ato de liberdade do sujeito atuante. Segundo Kant (KANT, 1995), o conhecimento fundado no ato imaginativo não é um conhecimento contaminado, pois é, simplesmente, o único conhecimento que temos. A coisa experimentada é um dado, mas a cognição humana concede a estrutura que a faz significativa. Se o mundo, sem a atividade mental de catego- 
Prof ${ }^{a} M^{a}$ Aparecida Camargo

[Unicruz ]
Prof ${ }^{\mathrm{a}}$ Ieda Linck

[Uncruz]

rização, seria caótico, a mente constituiria a realidade, tão somente em um sentido limitado. O prazer estético kantiano, assim, dá-se como resultado da congruência entre as duas faculdades cognitivas de imaginação e de entendimento.

Por sua vez, na ótica hegeliana (HEGEL, 1993, p. 490), o belo que se manifesta nas artes é essencial para a realização da "ideia absoluta", para a compreensão do mundo como é absolutamente. Arte é ideia absoluta manifesta aos sentidos, é a mente dada em forma sensível. Por isso, Hegel entende que o valor da arte está em sua capacidade de oferecer tanto uma forma adequada ao conteúdo ideal quanto à abstração deste. $\mathrm{O}$ valor artístico está, assim, relacionado com a eficácia da arte em elevar a mente à idealidade.

É oportuno verificar que a estética, de acordo com sua etimologia, tem valor ético, estabelece uma estratégia particular, pois se controla menos o mundo que não se goza. Tal gozo nunca pode ser individualista. $\mathrm{O}$ estético só tem qualidade quando é partilhável como expressão, conhecimento, comunicação. O estético, nesse sentido, significa vivência de intersubjetividade. Opera com estados vibráteis de interatividade, interfaces que produzam enlaces afetivos. Vibrações emocionais vividas com os outros exigem um acréscimo de atenção quanto à interação e contínua reciclagem das sensações para um apuro técnico no uso das emoções. De suas interfaces surgem os sentidos das significações, como menciona Meira (2003, p. 90).

Ainda de acordo com Hegel (1993, p. 492), as artes de configuração externa (material) mais clara seriam também as mais modestas em tal propósito, e aquelas que compartilham a interioridade desincorporada da mente, como a música, gozam de maior prestígio em sua filosofia. Enquanto as artes visuais criam presenças externas e objetos concretos espaciais, a música tem a capacidade de suprimir a distância entre quem percebe e aquilo que é percebido. Não consiste, pois, de imagens de coisas externas, mas de um campo de interioridade cujos padrões de tensão e repouso percebidos tornam patente a ascensão dialética da "alma" à liberdade da "ideia absoluta".

A música é, então, para Hegel (1993, p. 493), a arte do tempo, que, ao renunciar à espacialidade e à materialidade, livra a consciência das aparências externas e a harmoniza com a interioridade irrestrita da idealidade. Embora toda arte tenha origem na mente, a música seria altamente ideal, uma vez que seus "materiais" são, predominantemente, mentais e sua experiência mais interior e abstrata. Esta "vida interior" se manifesta tanto no conteúdo quanto na forma musical, sendo que os materiais envolvidos não devem ser de natureza permanente, como se fossem independentes. Obtém-se, assim, um modo de expressão 
Dnda. Vanessa Neubauer [Unisinos ]
Prof ${ }^{-a}{ }^{-a}$ Aparecida Camargo

[Unicruz ]
Prof ${ }^{\mathrm{a}}$ Ieda Linck

[Uncruz]

e de comunicação, em que a objetividade não entra como forma espacial, dotada de permanência, mas que é realizado com materiais sem resistência e que desaparecem logo após a sua utilização.

Nesse espaço sensório-estético estão inseridas as experiências musicais. Em consonância com Campbell, Campbell e Dickinson (2000, p. 132), a inteligência musical envolve suas próprias regras e estruturas de pensamento, não necessariamente vinculadas a outros tipos de inteligência. A música é uma linguagem auricular que usa três componentes básicos: som, ritmo e timbre ou qualidade de um som. É frequentemente escrita com sistemas simbólicos próprios. As inúmeras combinações desses três elementos deram origem à enorme variedade de música encontrada em todo o mundo.

Seguindo essa linha de pensamento, Gardner (1994) afirma que qualquer indivíduo que teve uma exposição frequente à música pode manipular o som, o ritmo e o timbre para participar com alguma habilidade de atividades musicais, incluindo a composição, o canto ou a execução de instrumentos. As bases de tais interesses podem ser lançadas em tenra idade. A música em casa e no ambiente inicial da vida proporciona uma base importante para essas experiências musicais que, mais tarde, podem ser integradas em todo o currículo escolar.

A arte musical é, em si, uma linguagem sonora em todas as culturas, podendo servir como fonte de inspiração, estimulando imagens e sentimentos e suscitando manifestações artísticas de todas as ordens. Promover as potencialidades musicais dos educandos é uma tarefa complexa no campo da educação como um todo. Para tanto, é preciso levar em consideração as afinidades criativas, o gosto e a exploração de novas formas de produzir sons, ao fomentar a inventividade. Nesse espaço interdisciplinar, de acordo com Meira (2003, p. 90), arte e filosofia são campos de estudo que dependem um do outro, assim como da política, do amor, da ciência, da espiritualidade. Estado de coisas, de corpos, de mentes, demência temperada, em planos potenciais se manifestam através de práticas criadoras, desde que possam contaminar-se uns aos outros.

\section{Sobre o entendimento do que seja a verdade na arte}

Como corolário, é imprescindível indagar se existe uma verdade na arte, haja vista que os cânones estéticos, mesmo hodiernamente, são ditados, reproduzidos e transmitidos pelas classes dirigentes. Assim, a arte é capaz de dizer 
Dnda. Vanessa Neubauer [Unisinos ]
Prof ${ }^{-a}{ }^{-a}$ Aparecida Camargo

[Unicruz ]
Prof ${ }^{\mathrm{a}}$ Ieda Linck

[Uncruz]

algo verdadeiro? Em consonância com a explicação de Feitosa (2004, p. 115), existem duas maneiras clássicas, paradigmáticas, de responder à questão. A primeira delas está representada pelo gesto platônico de expulsar os artistas de sua cidade perfeita, acusados de provocarem, ainda que involuntariamente, o engano e a ilusão. A comunidade perfeita é como um organismo em que cada participante contribui para o bem-estar geral. A saúde da cidade só começa a entrar em risco quando todas as tarefas e necessidades básicas já estão sendo cumpridas e começam a surgir desejos luxuosos, desnecessários. É nesse momento que surgem os artistas na cidade: poetas, músicos, dançarinos, pessoas que não desempenham função "realmente útil".

A arte só deveria ser praticada por crianças, mulheres, escravos e loucos, enfim, somente aqueles que não têm nada a perder. Essa depreciação platônica da arte, descrita em A República, fundamenta-se na suposição de que arte é sempre imitação. Para Platão (2001), a obra do artista não é apenas uma reprodução, mas algo inferior e inadequado tanto em relação aos objetos como às ideias que os pressupõem. O pintor somente é capaz de reproduzir superficialmente a materialidade dos objetos, sua aparência sensível.

Outra possibilidade de responder se a arte é capaz ou não de expressar a verdade, surgiu justamente de um dos alunos de Platão. Aristóteles procura mostrar que a arte é verdadeira, tanto do ponto de vista epistemológico, quanto moral. Essa virada é realizada sem que se abandone a ideia de que arte é imitação, ao contrário, ela se dá por intermédio de uma reinterpretação da mimese. Nesse sentido, a arte não é apenas reprodução, mas invenção do real. Além disso, a arte pode ter uma função idealizadora ou caricatural, como refere Feitosa (2004, pp. 120-121).

De acordo, ainda, com o mencionado autor (FEITOSA, 2004, p. 123), Aristóteles considera a arte necessária porque ela provoca um efeito benéfico denominado "catarse", um termo oriundo da medicina e que significa, literalmente, o processo de purgação dos elementos perniciosos presentes no corpo. Através da música, do teatro e da poesia, o espectador é incentivado a sentir fortes emoções. Enfim, a arte não apenas é capaz de nos trazer saber, ela tem também uma função edificante e pedagógica.

As manifestações artísticas, assim como as demais expressões culturais, têm seus objetivos próprios e, consequentemente, critérios de valor próprios. Entretanto, isso não conduz ao fato de que há uma verdade em arte. Isso foi inculcado no imaginário do senso comum pelas classes dirigentes para dominar, persuadir e impor uma cultura inacessível àqueles que se encontram em posição periférica na sociedade. Em contrapartida, é indispensável considerar que o valor esté- 
Prof ${ }^{a} M^{a}$ Aparecida Camargo

[Unicruz ]
Prof ${ }^{\mathrm{a}}$ Ieda Linck

[Uncruz]

tico de uma obra de arte independe de categorizações econômicas, mas sim das experiências que são oferecidas e oportunizadas pelas manifestações artísticas.

$\mathrm{Na}$ análise da verdade em arte, é relevante destacar as confrontações de Heidegger $(2010$, p. 87) quando utiliza como exemplo os sapatos de camponês de Van Gogh. Esses sapatos, no quadro, viram referência para qualquer sapato de camponês, pois neles algo se mostra com mais vigor do que aqueles utilizados pela camponesa. Assim, os sapatos de camponês ao surgirem na obra, enquanto arte, surgem como um acontecimento originário da verdade. Arte é, portanto, "o pôr-se em obra da verdade".

Perspectivando nesse caminho, o filósofo (HEIDEGGER, 2010, p. 87) enfatiza que o quadro de Van Gogh é a abertura daquilo que o utensílio, o par de sapatos do camponês é, em verdade. Este sendo (ente) emerge para o desvelamento do seu ser. Os gregos nomearam aletheia o desvelamento do sendo. Nós dizemos verdade e pensamos muito pouco em relação a esta palavra. Na pintura está em obra um acontecer da verdade, se aqui acontece uma abertura inaugurante do sendo naquilo que ele é e no como ele é. Na obra de arte, a verdade do sendo pôs-se em obra. "Pôr" diz aqui: trazer para o permanecer. Um sendo, um par de sapatos do camponês, vem, para o permanecer na luz do seu ser, na obra. O ser do sendo vem para o constante do seu brilhar. Então, a essência da arte seria esta: o pôr-se em obra da verdade do sendo.

No aludido exemplo, opera um nível de realidade que conduz à verdade do movimento de aparecer e ocultar-se do Ser. Dessa forma, Heidegger (2010), ao mesmo tempo em que indica um modo peculiar de contemplar uma obra de arte, também critica a maneira como esta obra é apreciada pelos indivíduos, os quais não entendem o que ela realmente significa. Diante da obra é mister se desapropriar do que é habitual, do que é comum para, assim, desvelar o artístico.

É fundamental sopesar que, consoante alerta Nunes (2005, p. 15), a arte excede, de muito, os limites das avaliações estéticas. Modo de ação produtiva do homem, ela é fenômeno social e parte da cultura. Está relacionada com a totalidade da existência humana, mantém íntimas conexões com o processo histórico e possui a sua própria história, dirigida que é por tendências que nascem, desenvolvem-se e morrem, e às quais correspondem estilos e formas definidos. Foco de convergência de valores religiosos, éticos, sociais e políticos, a arte vincula-se à religião, à moral e à sociedade como um todo, suscitando problemas de valor (axiológicos), tanto no âmbito da vida coletiva como no da existência individual, seja esta a do artista que cria a obra de arte, seja a do contemplador que sente os seus efeitos. 
Dnda. Vanessa Neubauer [Unisinos ]
Prof ${ }^{-a}{ }^{-a}$ Aparecida Camargo

[Unicruz ]
Prof ${ }^{\mathrm{a}}$ Ieda Linck

[Uncruz]

De acordo com Nunes (2005, p. 70), ainda, a arte, como forma simbólica, é uma forma de conhecimento para o artista que cria e para a consciência que contempla o produto de sua criação. Não possuindo a mesma universalidade do conhecimento científico, a arte goza, entretanto, de universalidade estética: está à disposição de quem pode fazer dela, como diria Kant (1995), uma objeto de satisfação desinteressada e universal, isto é, acessível a todas as consciências receptivas.

\section{Considerações finais}

É possível concordar com Gardner (1999, p. 23), quando este afirma que não acredita numa verdade, beleza ou moralidade singular ou incontestável. Todo período de tempo, toda cultura terão seus próprios favoritos provisórios e suas listas temporárias. Devemos começar com uma exploração dos ideais de nossa própria comunidade e também devemos estar informados sobre os ideais de outras comunidades. Podemos não endossar a estética do pós-modernismo, ou a moralidade do Islã fundamentalista, ou as verdades do Concílio Vaticano. Mas vivemos num mundo onde essas preferências existem e é necessário e conveniente aprendermos a conviver com elas e elas conosco.

A partir do exposto, pode-se analisar que a interpretação não é apenas um meio de produzir compreensão, mas também de abarcar o conteúdo do que ali se compreende. A arte possibilita a comunicação em sua essência totalizante, em um sentido mais amplo de reflexão e autonomia. Ao se refletir sobre os processos de circundação ontológicos, historicizados e de tradição, interpretando os sujeitos e suas consciências históricas, é possível contemplar a hermenêutica filosófica que envolve o campo da essência da arte.

Depreende-se, assim, que as experiências artísticas podem ser, efetivamente, instrumentalizadas por processos cognitivos. À medida que se entende que não existem verdades absolutas no espaço artístico e que, para haver uma transição paradigmática, é imprescindível repensar acerca dos cânones estéticos que estão postos, pode-se desconstruir muitos dos modelos dominantes tidos como naturais. Nesse campo educacional de multiplicidades de cognições, mostra-se fundamental inovar, buscar potencializar as habilidades artísticas, enfim, promover a criatividade, especialmente porque, nas artes pictóricas e musicais, tudo pode ser reconceitualizado a partir das experiências sensório-estéticas. 
Dnda. Vanessa Neubauer [Unisinos ]
Prof ${ }^{-a}$ Ma Aparecida Camargo

[Unicruz ]
Prof $\stackrel{\text { a }}{\text { Ieda Linck }}$

[Uncruz]

Para concluir, nada mais coerente do que trazer as palavras de Gadamer (2010, p. XIV), ao referir que de algum modo, sempre nos encontramos diante da arte como questão. Assim, ao nos aproximarmos de uma obra de arte, independentemente de essa aproximação se dar em um museu, em um anfiteatro ou em uma casa de espetáculo na qual escutamos alguém tocando uma peça qualquer ou declamando poesia, a primeira questão sempre se deixou formular: O que significa afinal o que agora está acontecendo?

Recebido em: 16.05.2014 |Aprovado em: 21.06.2014 $R$ Referência Bibliográfica

CAMARGO, Maria Aparecida Santana. Educação em Arte: desmitificando e ampliando concepções estéticas. Passo Fundo: Ed. Universidade de Passo Fundo, 2009.

CAMPBELL, Linda; CAMPBELL, Bruce; DICKINSON, Dee. Ensino e Aprendizagem por meio das Inteligências Múltiplas. 2. ed. Tradução de Magda França Lopes. Porto Alegre: Artmed, 2000.

FEITOSA, Charles. Explicando a Filosofia com Arte. Rio de Janeiro: Ediouro, 2004.

GADAMER, Hans-Georg. Hermenêutica da Obra de Arte. Seleção e Tradução Marco Antonio Casanova. São Paulo: WMF Martins Fontes, 2010.

. Verdade e Método. 9. ed. Tradução de Flávio Paulo Meurer. Petrópolis, RJ: Vozes; Bragança Paulista, SP: Editora Universitária São Francisco, 2007.

GARDNER, Howard. Estruturas da Mente: a Teoria das Inteligências Múltiplas. Porto Alegre: Artmed, 1994.

. O Verdadeiro, o Belo e o Bom: os princípios básicos para uma nova educação. Rio de Janeiro: Objetiva, 1999.
HEGEL, Georg Wilhelm Friedrich. Estética. Tradução de Álvaro Ribeiro e Orlando Vitorino. Lisboa: Guimarães Editores, 1993.

HEIDEGGER, Martin. Ser e Tempo. Petrópolis: Vozes, 2006.

.A Origem da Obra de Arte. Tradução de Idalina Azevedo e Manuel Antônio de castro. São Paulo: Edições 70, 2010.

KANT, Immanuel. Crítica da Faculdade do Juízo. 2. ed. Tradução de Valério Rohden e Antonio Marques. Rio de Janeiro: Forense Universitária, 1995.

MEIRA, Marly Ribeiro. Filosofia da Criação: reflexões sobre o sentido do possível. Porto Alegre: Mediação, 2003.

NUNES, Benedito. Introdução à Filosofia da Arte. 5. ed. São Paulo: Ática, 2005. (Série Fundamentos).

PLATÃO. A República. Lisboa: Calouste Gulbenkian, 2001.

TREVISAN, Armindo. Como Apreciar a Arte. Do saber ao sabor: uma sintese possivel. Porto Alegre: Mercado Aberto, 1990. (Série Novas perspectivas, v. 34). 